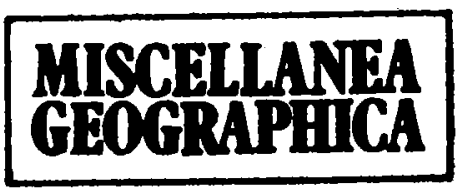

WARSZAWA 1990

\title{
Urszula Soczyńska
}

\section{PREDICTION OF DESIGN FLOODS IN UNGAUGED BASINS}

The paper discusses the application of the rational formula for design flood prediction in ungauged natural basins. There has been specified method for effective design storm intensity determination in function of the concentration time in the basin. The method has been tested in two small mountain basins. In spite of receiving fairly good results in comparison with the direct Dębski probability distribution function, there have been shown some imperfections of the rational formula and the directions of further investigations.

\section{INTRODUCTION}

The paper is a contribution to solving the problem of design flood simulation on the basis of storm analysis. The rational method used for years in practice requires continuation of research. The most important problems for consideration are as follows:

1. assumption of equality of exceedance probability of the design storm and the flood discharge respectively (Kidd, Packman 1980)

2. transformation of the design storm into the effective design storm,

3. determination of the effective storm intensity of specified exceedance probability and its duration equal to the concentration time $I_{E}\left(p, t_{c}\right)$, when $t_{c}$ itself is function of $I_{E}$,

4. significance of the initial conditions of stream-bed discharge in design flood determination.

The paper suggests a solution of problem (3), discusses problems (2) and (4) and indicates the further research directions as well as describes the adaptation of the Dimensionless Hydrograph Model (Chow, 1964) to simulation of the design flood hydrograph rising limbs. The results achieved have been tested in two small Carpatian basins. 


\section{CHARACTERISTICS OF THE BASINS}

The Soła river basin (Rajcza cross-section). Its area is $\mathrm{A}=254 \mathrm{~km}^{2}$. The gauging profile is situated $2 \mathrm{~km}$ below the fanshaped convergent, extended drainage systems of three mountaincreeks of order 5 . The basin is covered with forest in $50.3 \%$, arable grounds are $43.9 \%$. Mean basin slope $\mathrm{S}=52.7 \%$, length $\mathrm{L}=16.8 \mathrm{~km}$.

The Eososina river (Jakubowice cross-section). Its area is $\mathrm{A}=342.6$ $\mathrm{km}^{2}$. The shape of the basin is elongated and the stream network is of pinnate-dendritic character. Basin of order 6 . It is covered with forest in $24 \%$, arable ground are $76 \%$. Mean basin slope $S \equiv 49.8 \%$, length $\mathrm{L}=41.2 \mathrm{~km}$.

\section{DIMENSIONLESS HYDROGRAPH MODEL}

Following the kinematic wave equations, flow $(Q)$ in the river cross-section of order $\Omega$ (considered as order 1 for simplification) may be expressed:

$$
\mathrm{Q}=\alpha_{\Omega} \mathrm{F}_{\Omega}^{\mathrm{m}}
$$

where: $\alpha$ - kinematic wave parameter dependent on river profile parameters (Eagleson 1970), $F_{\Omega}$ - river cross-section of which the area above the baseflow may be determined by the product of the effective rainfall intensity $I_{E}$ and its duration $t\left(F_{\Omega}=I_{E}{ }^{*}\right.$ t); coefficient $m$ depends on flow regime and is equal to $5 / 3$ - for turbulent, 2 - for laminar and 3 - for mixed flow.

Substituting the expression for $F_{Q}$ to equation (1) we receive:

$$
\begin{aligned}
\mathrm{Q} & =\alpha_{\Omega} \mathrm{I}_{\mathrm{E}}^{\mathrm{m}} \mathrm{t}^{\mathrm{m}} & & \left(\mathrm{t}<\mathrm{t}_{\mathrm{C}}\right) \\
\mathrm{Q}_{\mathrm{M}} & =\alpha_{\Omega} \mathrm{I}_{\mathrm{E} \Omega} \mathrm{t}_{\mathrm{c}}^{\mathrm{m}} & & \left(\mathrm{t} \geqslant \mathrm{t}_{\mathrm{C}}\right)
\end{aligned}
$$

where $Q$ denotes flow after time to and $Q_{M}$ is the peak flow after effective rainfall duration equal or more then the concentration time. From the expression (2) we receive the simple relationship:

$$
\mathrm{Q} / \mathrm{Q}_{\mathrm{M}}=\left(\mathrm{t} / \mathrm{t}_{\mathrm{C}}\right)^{\mathrm{m}}
$$

describing the rising limb of the dimensionless hydrograph (DH). The form of this curve depends only on the flow regime expressed by coefficient $m$ (Nowicka, Soczyńska 1988) and may be used in any small 
basin. Application of the $\mathrm{DH}$ model is conditioned upon determination of two parameters $\left(Q_{M}\right.$ and $\left.t_{C}\right)$, which may be computed on the basis of physical basin characteristics and effective rainfall intensity. The peak flow $Q_{M}$ may be rewritten in the form of the rational formula. Putting $I_{E}$ in $(\mathrm{mm} / \mathrm{h})$ and the total basin area $A_{\Omega}$ in $\left(\mathrm{km}^{2}\right)$ we receive $Q_{M}$ in $\left(m^{3} / s\right)$ from the expression:

$$
\mathrm{Q}_{\mathrm{M}}=0.278 \mathrm{I}_{\mathrm{E}} \mathrm{A}_{\Omega}
$$

The equation for the concentration time computation may be drawn from solution of the kinematic wave model (Eagleson 1970):

$$
\mathrm{t}_{\mathrm{C}}=1.06 \frac{\mathrm{L}}{\alpha_{\Omega}^{0,6}\left(\mathrm{I}_{\mathrm{E}} \mathrm{A}_{\Omega}\right)^{0,4}}
$$

where the denominator represents kinematic wave celerity in $(\mathrm{m} / \mathrm{s})$, where $\alpha\left(\mathrm{s}^{-1} \mathrm{~m}^{-1 / 3}\right), \mathrm{I}_{\mathrm{E}}(\mathrm{mm} / \mathrm{h}), \mathrm{A}_{\Omega}\left(\mathrm{km}^{2}\right)$ and $\mathrm{L}(\mathrm{km})$ - length of the basin, $\mathrm{t}_{\mathrm{C}}(\mathrm{h})$.

The dimensionless Hydrograph Model has been tested in the above mentioned two basins on the registrated floods and results have been found quite satisfactory (Nowicka, Soczyńska 1988).

\section{DETERMINATION OF THE EFFECTIVE STORM INTENSITY IN THE FUNCTION OF PROBABILITY AND STORM DURATION $\left(I_{\mathrm{E}}\left(p, t_{c}\right)\right)$}

Relationship of storm intensity with probability and time duration has been computed after Lambor (1971) formula and is illustrated in Figure 1. The next step was determination of the effective storm intensity. For this reason the SCS method has been used. The only parameter of this method CN depends on soil kind, soil use and preceding wetness conditions of the basin and it is very difficult to determine it in an objective way. It takes values in a very wide range $<0.100>$ and simultaneously very small changes of it cause very important changes of the effective rainfall. Figure 2 has shown the dependence of the runoff coefficient on rainfall depth $\mathrm{P}$ and $\mathrm{CN}$ parameter in the range $<40.90>$. This immense sensitivity of the runoff coefficient to the CN parameter requires a very careful analysis of its determination. In the work the CN parameter has been estimated from the flood analysis. In both basins its mean value oscilated about 85 . Figure 3 illustrates the relationship $I_{E}(p, t)$ in the Eososina and Soła basins at $\mathrm{CN}=85$. 


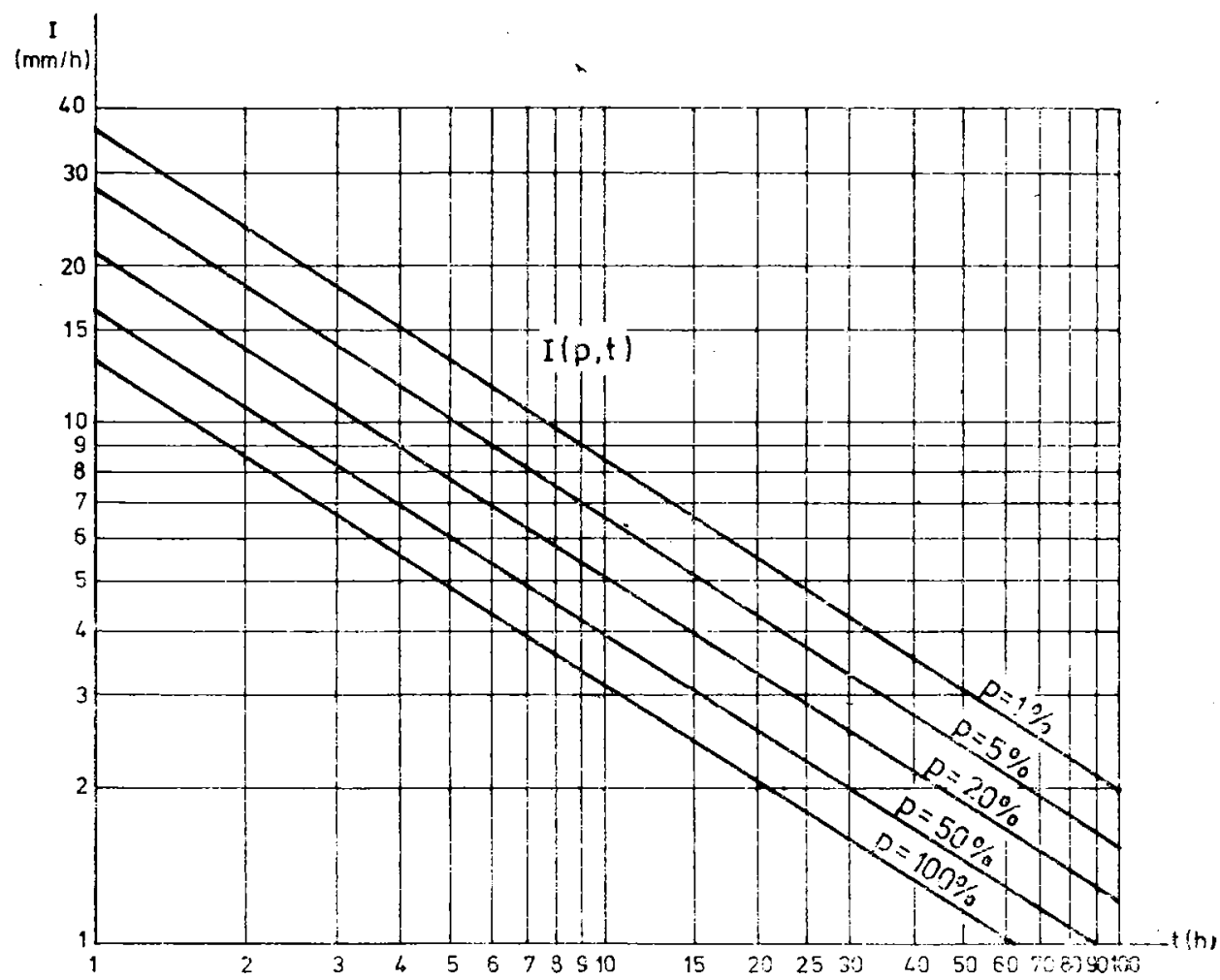

Fig. 1. Dependence of the storm intensity on probability and storm duration I(p, t) (after Lambor, 1971)

\section{DETERMINATION OF THE EFFECTIVE STORM INTENSITY OF PROBABILITY P AND STORM DURATION EQUAL TO THE CONCENTRATION TIME $I_{\mathrm{F}}\left(p, t_{c}\right)$}

According to the foundation of the rational formula, the maximum flow $Q_{M}$ responds to the effective storm intensity $I_{E}$, of time duration equal to concentration time $t_{c}$. Taking into account that the concentration time itself depends on the effective storm intensity, its determination forms some kind of the non-solving loop. Many authors go then to methods estimating the concentration time according to the physiographic features only. This problem, however, may be solved by determination of the relationship of the concentration time versus the effective storm intensity $t_{c}\left(I_{E}\right)-$ eq. (5), and plotting it on the diagram $I_{E}(p, t)$. Points of the intersection of the respective curves will univocally assign the magnitude of desired effective storm intensity of specified probability and respective concentration time $I_{E}\left(p, t_{c}\right)$. Figure 3 shows an example of solving of this problem in the Sola and Eososina basins. 


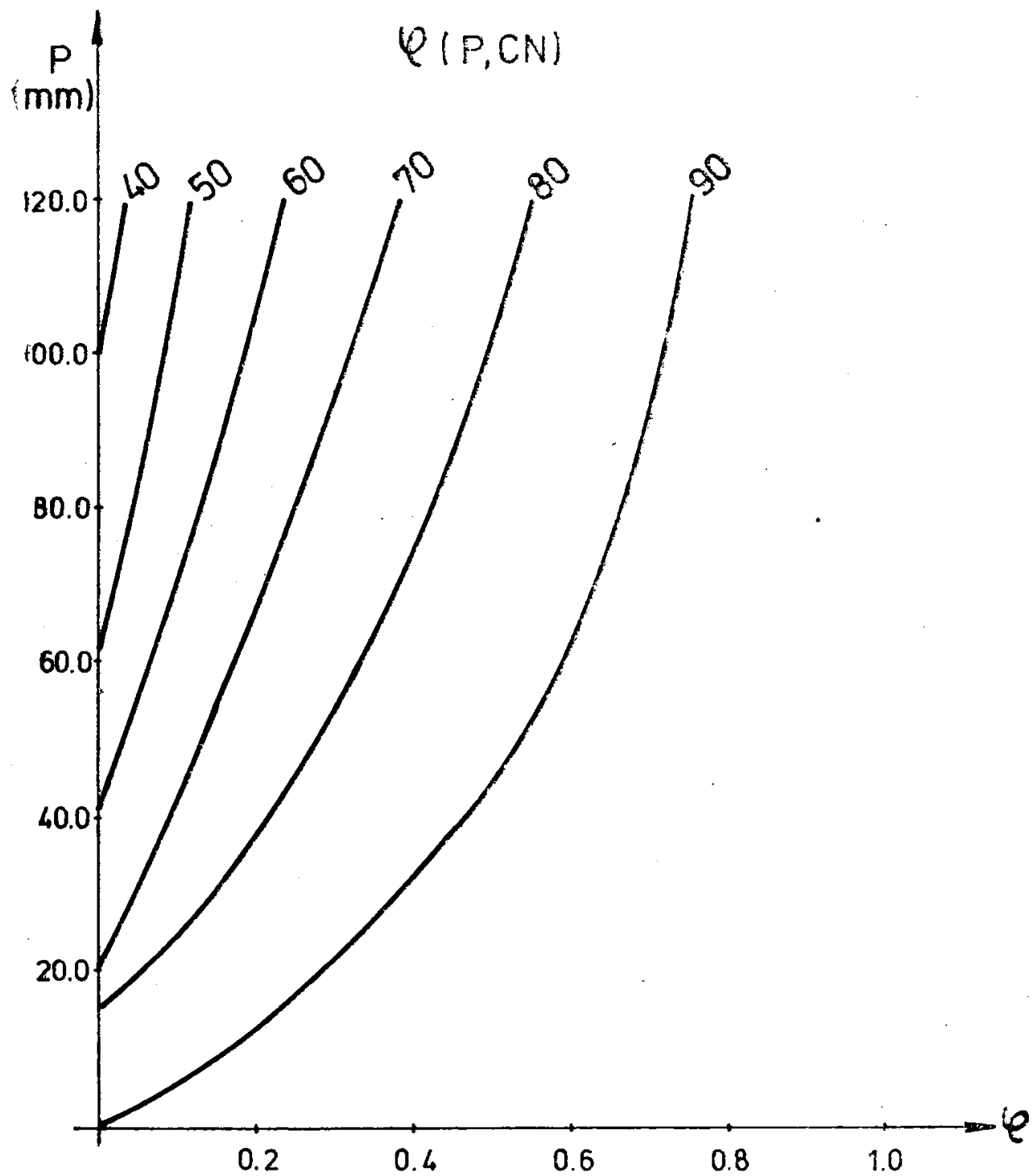

Fig. 2. Dependence of the runoff coefficient on storm depth and CN parameter in SCS method 


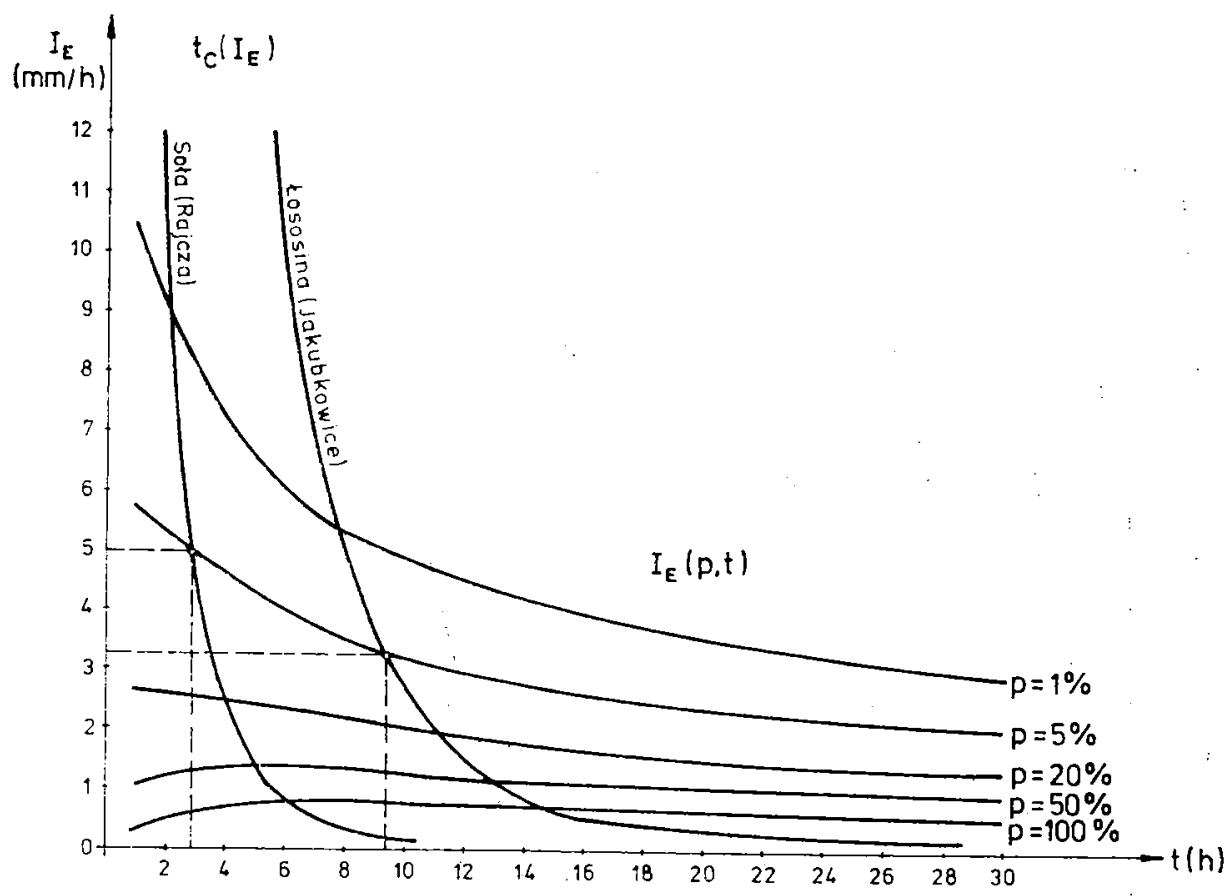

Fig. 3. Method of effective storm intensity determination in dependence: on probability and concentration time $I_{E}\left(p, t_{c}\right)$

\section{DETERMINATION OF THE DESIGN FLOOD HYDROGRAPHS}

The maximum flows of specified probability have been determined after formula (4) using figure (4) for estimation of the respective effective storm intensity in function of probability $I_{E}\left(p, t_{c}\right)$. The computed values in the Sola and Eososina basins are shown in Table 1 and compared with resepective values calculated after Dębski probability distribution function (Dębski 1954). The maximum differences show estimations of the $Q_{1}$ (the error $\delta>30 \%$ ), and $Q_{50}$ is estimated with accuracy $11 \%$ in Eososina and 18\% in Sola river. For estimation of the $\mathrm{CN}$ parameter influence on the resepective quantities estimation, they have been computed at $\mathrm{CN}=80$ and $\mathrm{CN}=87,6$. Generally, the best results have been received at $\mathrm{CN}=85$, but at $\mathrm{CN}=87,6$ the error of estimation of $Q_{50}$ in the Sola river decreased to $5 \%$ but due to the $Q_{1}$ increased to $68 \%$. In the Easosina river at $\mathrm{CN}=80$ there has been received considerable improvement in estimation of $Q_{1}\left(\sigma=3,6^{\%} \%\right)$ and $Q_{20}(\delta=3,0 \%)$, however the error of $Q_{50}$ estimation increased up to $31 \%$ 


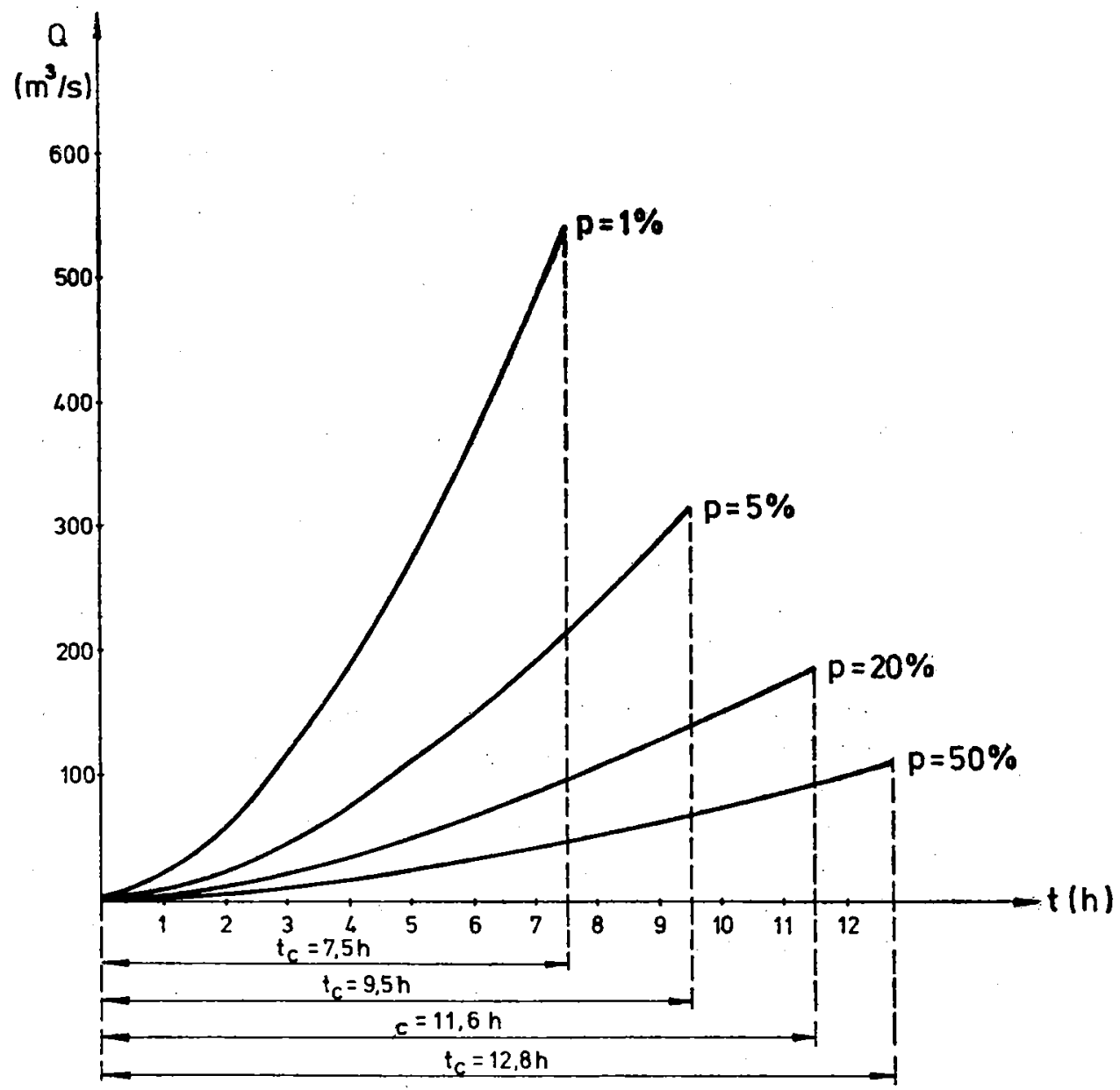

Fig. 4. Hydrographs rising limbs of specified probability $p$ (Eososina. river, Jakubkowice section)

Results of the analysis show that the $\mathrm{CN}$ parameter is also dependent on the magnitude of flood so it is connected with its probability.

During the last phase of the work using the foundations of the $\mathrm{Di}$ inensionless Hydrograph, the hydrograph rising limbs of specified pro bability $p$ have been computed; as an example they are shown in figure 4 for the Eososina basin.

\section{CONCLUSIONS}

One of the very important problems in the design flood estimation from storm analysis is determination of the effective design storm. The 
Comparison of the design floods $Q_{p}\left(\mathrm{~m}^{3} / \mathrm{s}\right)$ computed after Dębski pdf and the rational method $(C N=85)$

\begin{tabular}{|cccccccccc|}
\hline \multicolumn{3}{c}{$\begin{array}{c}\text { Sola river } \\
\text { (Rajcza cross-section) }\end{array}$} & \multicolumn{5}{c}{$\begin{array}{c}\text { Eososina river } \\
\text { Jakubkowice cross-section }\end{array}$} \\
\hline $\begin{array}{c}\mathbf{Q}_{\mathrm{p}} \\
\text { after } \\
\text { Dębski }\end{array}$ & $\mathrm{Q}_{\mathrm{p}}$ & $\Delta \mathrm{Q}_{\mathrm{p}}$ & $\delta$ & $\mathrm{p}(\%)$ & $\begin{array}{c}\mathrm{Q}_{\mathrm{p}} \\
\text { Deqbski } \\
\text { after }\end{array}$ & $\mathrm{Q}_{\mathrm{p}}$ & $\Delta \mathrm{Q}_{\mathrm{p}}$ & $\delta$ \\
\hline 490,3 & 649.5 & 159.3 & 0.32 & 1 & 390.8 & 542.9 & 152.1 & 0.39 \\
\hline 344,5 & 353.0 & 8.5 & 0.02 & 5 & 278.0 & 314.3 & 36.3 & 0.13 \\
\hline 214,3 & 176.5 & -37.8 & 0.18 & 20 & 176.7 & 185.7 & 9.0 & 0.05 \\
\hline 121,0 & 98.8 & -22.2 & 0.18 & 50 & 103.9 & 114.3 & 11.3 & 0.11 \\
\hline
\end{tabular}

runof: coefficient (similarly as the $\mathrm{CN}$ parameter of the SCS method) is connected with the storm probability and cannot be assumed as the stable value in the basin.

In spite of receiving fairly good results some doubts arise in application of the standard form of the rational formula in natural basins. The maximum flow calculated from it is the overland flow only, while the design flood flow is the total one including both the overland and the base part of flow. The rational formula should be then extended to the form:

$$
\mathrm{Q}_{\mathrm{M}}=\mathrm{Q}_{\mathrm{o}}+0,278 \mathrm{I}_{\mathrm{E}} \mathrm{A}_{\Omega}
$$

where $Q_{0}$ denotes the base flow. However this formula gives overestimation of the design flood. It is probably caused by using the total basin $A_{2}$ as a contributing area, which in the natural basins is not valid. This is also the problem to be solved in the future. So far the rational formula cannot yet be recommended to design flood predictions in ungauged natural basins.

\section{REFERENCES}

Chow, V. T., 1964, Handbook of Applied Hydrology, N. York, S. Francisco, Toronto, London.

Debski, K., 1954, Probability of the hydrological and meteorological phenomena. Method of deciles (in Polish), Warsaw.

Eagles o n, P.S., 1970, Dynamic Hydrology, N. York. 
$\mathrm{Kidd}$, CHR, P a ckman, J. C., 1980, „Selection of design storm and antecedent condition for urban drainage design", Institute of Hydrology, Wallingford, Report No. 61.

L a mbor, J., 1971, Hydrologia dla inżynierów (Hydrology for Engineers) Arkady, Warszawa.

Nowi cka, B., Soczyńska, U, 1988, „Overland flow determination by geomorphologic and hydrodynamic models", Miscellanea Geographica, Warsaw University.

$\mathbf{L}$ 
